This item was submitted to Loughborough's Research Repository by the author.

Items in Figshare are protected by copyright, with all rights reserved, unless otherwise indicated.

\title{
Cushioning and lateral stability functions of cloth sport shoes
}

PLEASE CITE THE PUBLISHED VERSION

http://dx.doi.org/10.1080/14763140701491476

\section{PUBLISHER}

(c) Taylor \& Francis

\section{VERSION}

AM (Accepted Manuscript)

\section{PUBLISHER STATEMENT}

This work is made available according to the conditions of the Creative Commons Attribution-NonCommercialNoDerivatives 4.0 International (CC BY-NC-ND 4.0) licence. Full details of this licence are available at: https://creativecommons.org/licenses/by-nc-nd/4.0/

\section{LICENCE}

CC BY-NC-ND 4.0

\section{REPOSITORY RECORD}

Fong, Daniel Tik-Pui, Youlian Hong, and Jing-Xian Li. 2019. "Cushioning and Lateral Stability Functions of Cloth Sport Shoes". figshare. https://hdl.handle.net/2134/21254. 


\begin{tabular}{|l|l|}
\hline Title & $\begin{array}{l}\text { Protective functions of cloth sport shoe for school children participating } \\
\text { in general exercises in physical education lessons }\end{array}$ \\
\hline Running title & Protective functions of cloth sport shoe \\
\hline Keywords & $\begin{array}{l}\text { Cloth Sport Shoe, Canvas Shoe, Human Pendulum, Cushioning, } \\
\text { Lateral Stability, Cutting Movement }\end{array}$ \\
\hline
\end{tabular}




\section{Abstract:}

This study evaluated the protective functions of cloth sport shoe for school children participating in general exercises in physical education lessons. Twelve male students participated in this study (age: $12.7 \pm 0.4 \mathrm{yrs}$; mass: $40.7 \pm 5.9 \mathrm{~kg}$; height: $150.4 \pm 4.25 \mathrm{~cm})$. Cloth sport shoe, running shoe, basketball shoe, cross-training shoe and barefoot conditions were investigated in random sequence. Human pendulum and cutting movement test were used in assessing cushioning performance and lateral stability respectively. In cushioning, running shoe $(2.06 \mathrm{BW})$ performed the best, while cross-training shoe (2.30BW) and basketball shoe (2.37BW) both performed better than cloth sport shoe $(2.55 \mathrm{BW})$ and barefoot $(2.63 \mathrm{BW})$. In lateral stability test, no significant different were found between all conditions but prolonged duration from foot strike to maximum inversion was found in cloth sport shoe trials (66-95ms), which was unlikely to evoke intrinsic stability failure. However, neither beneficial nor harmful effects could be demonstrated. In conclusion, cloth sport shoe showed inferior cushioning capability but no lateral stability deficient when compared with other sports shoe in general exercises in physical education lessons. If high intensity running with repetitive heel impact is not involved, cloth sport shoe should be adequate in protective functions for school children.

\section{Introduction:}

The role of sports shoe is to enhance sports performance and prevent the athletes from getting injured. Footwear biomechanics is a rapid developing science in recent decades that helps understanding the effect of sports shoe and the design of suitable sports shoes. Orthopaedics and biomechanics 
scientists are actively working on biomechanical assessments of the functions of footwear. These studies investigated traction and torsion between footwear and playing surfaces (Torg et al., 1974; Stacoff et al., 1991), physiological and ergonomics factors (Frederick, 1984), lateral stability (Luethi et al., 1986), cushioning ability (Nigg et al., 1988), cardiorespiratory responses (Hamill et al., 1988), relationship between injuries and shoe construction (Stacoff et al., 1988), inside-shoe pressure distribution (Hennig and Milani, 1995), effect on perception (Hennig et al., 1996), effect on performance (Brizuela et al., 1997), and shoe comfort (Mundermann et al., 2002). Among these functions, elite athletes may place slightly more emphasis on performance, while general sports practitioners should concern more about injury prevention (Lake, 2000).

Shock absorbing and lateral stability are the two essential protective functions of sports shoes (Lake, 2000). Sports shoes can be identified in two major categories, running shoes and court shoes (Martin, 1997). Running shoes mainly provide cushioning by thick midsole, while such design is absence in court shoe as it introduces instability. There is also a type of cross-training shoe which combines some elements of both running and court shoes. It is moderately successful in all sports types and functions well as a walking shoe (Martin, 1997).

Impact force is defined as the force generated by a collision between two objects that reaches its maximum within 50 ms after first contact (Nigg and Herzog, 1994). In running, the peak vertical impact force between the ground and the foot in the first $20-30 \mathrm{~ms}$ after the foot strike was found to be two to three times the runner's weight (Munro et al., 1987). Repetitive impact force 
may cause lower limb injury (Barnes and Smith, 1994) and low back pain (Voloshin and Wosk, 1982). Therefore regular runners should equip themselves with suitable running shoes that can cushion the impact force during foot strike. In courts games such as basketball, tennis and volleyball games, the most common injury is ankle sprain, which account for as much as $80 \%$ of the total injuries sustained (Garrick, 1977). It is caused by excessive inversion moment at ankle, which exceeds the internal eversion moment provided by the everter muscles and ligaments (Stacoff et al., 1996). The peroneal muscles at ankle joint give stability. However the reaction time of these muscles is often too slow to prevent sprain injury (Konradsen and Ravn, 1991; Karlsson et al., 1992). To prevent ankle sprain occurrence, lateral stability and support is necessary for athletes participating in court games, especially at the critical duration right after foot strike and before the peroneal muscles react (Simpson et al., 1992). Therefore court game athletes should have suitable court shoes to prevent ankle sprain injury.

The best way to prevent both impact peak related injury and ankle sprain is to have a footwear that can provide both good cushioning and lateral stability. However it was found that there is a trade off between shock absorption ability and lateral stability in footwear. High-cut upper design in court shoes may provide good stability. However at the same time it reduces the cushioning effect as they limit the range of ankle plantarflexion and inversion movement (Brizuela et al., 1997). In landing after a vertical jump with ankle range of motion restricted, cushioning capability is reduced and the peak impact force could reach as much as six times the body weight (McClay et al., 1994). Sports shoe with thick midsole may provide good cushioning. However it increases 
the level arm length when the athlete performs lateral cutting and lands on either medial or lateral edges of the shoe. The increased arm length then increases the external torque acting on the ankle joint, and thus introduced instability (Stacoff et al., 1988). Therefore we do not have a type of shoes providing excellent cushioning and excellent lateral stability at the same time.

In Hong Kong, most school children wear cloth sport shoes in physical education lessons. Cloth sport shoe, also named as canvas shoe or just cloth shoe, is a kind of low-price, light and highly flexible shoe with thin shoe sole and cloth upper sole. The average price of this shoe is HK\$30 or US\$ 4 only. Since the cloth sport shoe is inexpensive and it is often pure white in color, school students are often requested to wear it for physical education lessons as a uniform (Figure 1, top left). Recently, concern has been raised on the protective function of cloth sport shoe from physical education instructors, sports scientists, allied health professionals, parents and students. However, despite the rising concerns, the protective function of cloth sport shoe is still left uninvestigated.

Previous studies investigated the cushioning ability and lateral stability of different athletic footwear. Those tests included running test on force platform (Munro et al., 1987), human drop test (Jorgensen and Ekstrand, 1988), vertical landing test (Brizuela et al., 1997), human pendulum test (Lafortune and Lake, 1995), and sideward cuttiing test (Stacoff et al., 1996). The present study aims investigate the cushioning ability and lateral stability of cloth sports shoe, and to compare the performance with running shoe, court shoe, cross-training shoe and barefoot situation. Human pendulum was employed in cushioning 
test, and a cutting movement test was employed in the lateral stability assessment. The findings will give the general public some information about the protective functions of such footwear that is currently widely used by the school children for exercising.

\section{Method:}

A survey was conducted to investigate 288 local school children aging from eleven to twelve to see the popularity of athletic shoes they wear in physical education lesson. The questionnaires were distributed by physical education instructors in ten local primary schools. The students were asked for their choice of shoes in physical education lessons, and the expense for purchasing their shoes.

Twelve male subjects (mean \pm S.D.: age: $12.7 \pm 0.4$ yrs; mass: $40.7 \pm 5.9 \mathrm{~kg}$; height: $150.4 \pm 4.25 \mathrm{~cm}$ ) participated in this study. The subjects wear cloth sport shoes with size 38.5 (length $=26 \mathrm{~cm}$ ). They were recruited from local primary schools. They participate in some running and also some court games during physical education lessons in school. The subjects were free of injury and pain on the testing day. Written informed consents were obtained from all subjects before the study. The university ethics committee approved the study.

Five shod conditions (cloth sport shoe, running shoe, basketball shoe, cross-training shoe, barefoot) were tested in a random sequence (Figure 1). The shoes were all commercially available and were considered as representatives of its specific sports shoe category. The shoe category was 
identified by the product information provided by the manufacturer. Basketball shoe was chosen to represent court shoe. A human pendulum was employed in this study (Figure 2). The pendulum consisted of a lightweight bed suspended by four wires from a hanging structure. The hanging structure, constructed by the university construction work unit, was a metal frame which was fixed on concrete wall at a height of $3.8 \mathrm{~m}$ which can support at least $100 \mathrm{~kg}$ of weight. The supporting wires were $3.2 \mathrm{~m}$ in length. The lightweight bed and the four supporting wires acted like a swinging pendulum. A force plate (Kistler 9281CA, Switzerland) was vertically mounted on a concrete wall via a metal mounting frame. A velocity transducer (Celesco DV301-0075-111-1110, USA) was installed beneath the force plate to measure the horizontal impacting velocity of the bed (not shown in Figure 2). Each subject laid supine on the bed with left leg extending over the edge of the bed. A cushion was placed beneath the left shank to facilitate a heel impact on force plate. The right leg was flexed to avoid contacting the force plate during experiment.

In order to mimic the impact during mild intensity running which the school children often perform in physical education lessons, the bed was adjusted to be released at a certain position (about $0.71 \mathrm{~m}$ from the force plate) which resulted in an impact velocity of $1.15 \mathrm{~ms}^{-1}$ on the force plate. This impact velocity equals the vertical impact velocity during every heel strike in running at a velocity of $3.6 \mathrm{~ms}^{-1}$ (Cavanagh et al., 1984). Such chosen impact velocity in human pendulum experiment was found to be able to well represent the lower limb biomechanics during normal running on level surface (Lafortune and Lake, 1995). The impact velocity during every trial was monitored by the velocity 
transducer. If the impact velocity did not fall within the range between 1.13-1.17 $\mathrm{ms}^{-1}$, the trial was discarded and was conducted again with suitable adjustment on the release position. The force plate and the velocity transducer were connected to a computer for data collection at $1000 \mathrm{~Hz}$ via LabVIEW program. Body weight of each subject was measured by a floor-mounted force plate which was described in the lateral stability test protocol. The peak impact force was normalized to the bodyweight of the subject. The normalized peak impact force and the time to peak impact force in all shod conditions were compared.

Lateral stability test followed the cushioning test. The same five shod conditions were tested in random sequence. Three reflective skin markers were attached to the left rearfoot of each subject at the position of calcaneus (A), achilles tendon (B), and $5 \mathrm{~cm}$ above marker $B$ along the center of leg $(C)$. The line joining marker $A$ and $B$ and the line joining marker $B$ and $C$ in frontal plane defined the heel angle showing inversion and eversion (Figure 3). A window was cut around the heel counter of each testing shoe to allow the calcaneus marker to be seen from outside. Each subject started at the starting line and performed ten forward and sideward cutting movements (Figure 4) with a three-step run up towards the filming area on a floor-mounted force platform with the foot aligning within 5 degrees with the camera axis, which was the sagittal axis (Stacoff et al., 1996). Wooden plates with same height as the force plate were placed around to provide a level surface for the test. The foot alignment was visually checked by a research staff standing right behind the sagittal axis during each trial. If the foot did not align within 5 degrees along the camera axis, the trial was discarded and was performed again. A rhythm 
machine was used to produce a sound beat for the subjects to control their step frequency. As suggested by physical education instructor, the frequency was set at 100 beats per minute as this should well represent the intensity of mild cutting motions the students perform in lessons. Subjects were instructed to follow the beat frequency to perform the four-step cutting motions from the starting line. Practice was allowed for subjects to get familiar with the running frequency and speed.

The motions were filmed by four high-speed video cameras (JVC 9600, Japan) at $100 \mathrm{~Hz}$. The floor-mounted force plate (Kistler 9281CA, Switzerland) simultaneously recorded the ground reaction force during foot contact at $1000 \mathrm{~Hz}$ and the data was transferred to a computer and recorded via LabVIEW program. The foot contact duration was determined when the vertical ground reaction force exceeded $20 \mathrm{~N}$. In order to synchronize the video data and the force plate data, a synchronization switch was used to light up four small bulbs which were placed right in front of the cameras, and to output a square wave signal to the computer at the same time. Video data were processed by motion analysis system (APAS, USA). The video were trimmed from 10 frames before foot strike to 10 frames after takeoff. The video frames were automatically digitized with manual check. To minimize digitizing error, each trial was digitized ten times and the standard deviation for this heel angle was less than \pm 0.5 degrees (Stacoff et al., 1996). The heel angle was obtained by the line joining marker $A$ and $B$ and the line joining marker $B$ and $C$. The time from foot strike to maximum inversion was also determined. Lateral stability of each shoe was compared by the range of ankle inversion as represented by the heel angle after touchdown. The range of inversion and the 
time to maximum inversion in all shod conditions were compared.

Multivariate analysis of variance (MANOVA) with repeated measures was applied to see significant difference among the five shod conditions. If significant difference was found in any of the dependent variables, pairwise post-hoc Tukey test was applied to further determine difference among each pair of shod conditions.

\section{Results:}

The popularity and the average price of the sports shoe used by the school children in physical education lessons were shown in table 1. Most students (37\%) used to wear cloth sport shoe for lessons. However there was still comparable popularity of cross-training shoe (31\%) and also running shoe $(21 \%)$.

The descriptive statistics and the results of ANOVA of the cushioning and lateral stability parameters were shown in table 2. MANOVA showed that the different shod conditions had significant effect on all dependent variable in overall (Wilks' Lambda $=.251, \mathrm{~F}=3.186, \mathrm{p}=.000$ ). ANOVA showed that the effect was on the normalized peak impact force only $(p<.01)$.

The Tukey pairwise comparison further revealed any significant difference among each pair of shod conditions as shown in table 3. From the results, the normalized impact force in running shoe was significantly lower than all other situations $(p<.01)$. The cross-training shoe, having the second lowest 
normalized impact force recorded, significantly differed from cloth sport shoe $(p<.05)$ and also barefoot $(p<.05)$ but not basketball shoe. Basketball shoe, which ranked third in the ascending order of normalized impact force, significantly performed better than barefoot $(p<.05)$. However its normalized impact force was just slightly lower than that of cloth sport shoe which was only barely significant $(p=.067)$. Cloth sport shoe could only attenuate the normalized impact force by a value of $0.08 \mathrm{BW}$, which was not statistically significant. It was also inferior in cushioning compared with running shoe ( $p$ $<.05)$ and cross-training shoe $(p<.05)$. All shoes but not cloth sport shoe was found to have significant cushioning effect compared to barefoot situation ( $p$ $<.05)$

\section{Discussion and implications:}

In this study the inversion angles in the cutting test ranged from 3.63 degrees in basketball shoe to 4.89 degrees in barefoot. Although the court shoe showed a reduction of ankle inversion compared to other conditions, the effect was not significant. In Stacoff's study (Stacoff et al., 1996), the heel inversion angle was found to be about 20 degrees. The major difference between this study and Stacoff's is the age of the subject. In Stacoff's study, the subjects were 25-year old male adults who had performed numerous sideward cutting movements during their athletic careers. In this study the subjects were 12-year old male school children who participate in only school physical education exercises. The cutting motions of the adult subjects were expected to be more vigorous. This may be one of the reasons of the resultant larger inversion angle. Moreover, the running speed in Stacoff's study was neither controlled nor reported. In this study the running was somewhat controlled by a 
rhythm machine. Subjects were instructed to run with same step frequency. Although the subject may have different step length and thus resulting in different running speed, the authors considered that it was acceptable as it is often very difficult to monitor running speed when a test could not be done on treadmill. The adult subjects were expected to run with a higher speed that resulted in more vigorous cutting motions and thus larger inversion angles.

The time from foot strike to maximum inversion ranged from $66.00 \mathrm{~ms}$ in basketball shoe to $95.45 \mathrm{~ms}$ in barefoot in this study. In Stacoff's study (Stacoff et al., 1996), the time were all within $40 \mathrm{~ms}$ after touchdown. This confirmed that the cutting motions of those adults were more vigorous. Another important message from this finding was the prolonged ankle inversion motion, which was unlikely to evoke intrinsic stability failure. For stable ankle joint, Konradsen and Ravn reported that the reaction times of peroneal longus and peroneal brevis were 65 ms and 69 ms (Konradsen and Ravn, 1991), while Karlsson reported $68.8 \mathrm{~ms}$ and $69.2 \mathrm{~ms}$ respectively (Karlsson et al., 1992). In this study, as the time of the inversion ranged from 66.00 to $95.45 \mathrm{~ms}$, the peroneal muscles should have enough time to react and provide necessary eversion torque at ankle joint to balance or external inversion torque. Therefore all shod conditions investigated in this study should be adequate for school children performing mild cutting motions in physical education lessons. However for adult athletes performing more vigorous cutting motions, there may be a failure of peroneal reaction and thus more emphasis should be put on proper footwear for sprain prevention.

However, the inferior cushioning effect of cloth sport shoe should be noted. 
From this study, the cloth sport shoe was able to attenuate only $0.08 \mathrm{BW}$ compared with barefoot condition. Moreover such different was not significant. The running shoe reduced the normalized peak impact peak from $2.63 \mathrm{BW}$ to 2.06 BW. It reduced almost half of the body weight of the subject. From the results of cushioning test and, we categorized the four shod conditions into excellent, good and fair classes for school physical education lessons (Table 4). The running shoe was classified as excellent in cushioning, while the cross-training shoe and basketball shoe were classified as good. The cloth sport shoe did not provide significant cushioning effect and thus was classified as fair. In lateral stability test, since the intensity of cutting motions in school physical education lessons was low in intensity, the stability provided by the footwear was not prominent and thus no classification was done.

Human pendulum was used to assess the cushioning ability (Lafortune and Lake, 1995). Previous study revealed the perception effect on running styles to avoid high heel impacts (Milani et al., 1997). When human anticipates high heel impact when landing on hard surface or in barefoot situation, human alters the lower extremity biomechanics to reduce the impact force. In order to study only the effect introduced by different footwear in cushioning, the self-protective perception effect should be removed. There was also a method using instrumented missiles for controlled impact test in simulated running heel strike (Aerts and De Clercq, 1993). However the maximal peak force generated was only $864 \mathrm{~N}$, which was still far less than the impact force during running, which was found to be about $1270 \mathrm{~N}$ (Munro et al., 1987). The human pendulum approach can generate comparable impact magnitude (Lafortune and Lake, 1995) and can remove the perception effect of lower limb impact 
loading severity, and thus providing better control of the lower limb biomechanics during cushioning assessment (Lake and Lafortune, 1998). Therefore this approached was employed in this study.

Biomechanists often consider that foot is a sensory organ to detect the external environmental condition for balance adaptation and also dynamic gait balance (Lord and Bashford, 1996). However parents often purchase unnecessary shoes for their children from infants. A study in 1981 in the United States revealed that infants started receiving their first pair of walking shoe at an average age of 8.1 months, and the cost ranged from US $\$ 2$ to US\$43 (Weiss et al., 1981). Of the 104 surveyed children, 73 of them had their shoes before they were walking, and 35 had theirs before they were even standing. In the same study, $77 \%$ of pediatricians considered that inexpensive canvas sneakers which allow flexibility while protecting the foot from minor trauma are adequate for infants with normal feet. For older adults, a study in 2004 revealed that those older adults who wear canvas shoes were associated with the lowest falling risk (Koepsell et al., 2004). For therapeutic purposes, canvas shoes were introduced to leprosy patients who had retarded foot sensation capability (Wiseman, 1990). Therefore the thin sole design of cloth sport shoe or canvas shoe plays an important role to enhance foot sensation, especially in infant, elderly and patient populations.

Although the cloth sport shoe showed inferior capability in shock absorption, we could not conclude that if it introduces harmful effect for school children participating in physical education lessons. We suggest that for general school children participating in school physical education lessons which mild intensity 
running and cutting motions are involved, a pair of cloth sport shoe deems to be adequate. However for school children who are engaged in regular running practice, the use of cloth sport shoe may introduce repeated high impact on heel during every foot strike. Therefore these regular young runners should consider purchasing a pair of running shoe which can significantly reduce the impact peak during running.

\section{Conclusion:}

Cloth sport shoe showed inferior capability in cushioning for school children participating in running at a speed of $3.6 \mathrm{~ms}^{-1}$ but showed no significant difference in lateral stability with other shoe types in mild cutting motions. The ankle inversion during cutting motions performed by school children was too slow to introduce peroneal muscle reaction failure. Therefore the cloth sport shoe was considered to be adequate for general exercise in primary school physical education lessons.

Neither beneficial nor harmful effects could be demonstrated from this study. As previous studies showed beneficial effect of wearing cloth or canvas shoe with thin sole design in infant, elderly and patients with retarded foot sensation, we believe that young school children may gain similar effect when they wear cloth sport shoe for low intensity physical activity. However for regular young runners, we recommend purchasing suitable running shoe which could reduce the repetitive high impact on heel during every foot strike.

This study provided some information about the protective functions of cloth sport shoe for school children during school physical education lessons. 
Further studies on the long-term effect on foot sensation development, balance ability, injury risk and perhaps prevention of osteoporosis of cloth sport shoe usage for general or specific exercises and populations are suggested.

\section{References:}

Aerts, P., and De Clercq, D. (1993). Deformation characteristics of the heel region of the shod foot during a simulated heel strike: the effect of varying midsole hardness. Journal of Sports Sciences, 11, 449-461.

Barnes, R. A., and Smith, P. D. (1994). The role of footwear in minimizing lower limb injury. Journal of Sports Sciences, 12, 341-353.

Brizuela, G., Llana, S., Ferrandis, R., and Garcia-Belenguer, A. C. (1997). The influence of basketball shoes with increased ankle support on shock attenuation and performance in running and jumping. Journal of Sports Sciences, 15, 505-515.

Cavanagh, P. R., Valiant, G. A., and Misevich, K. W. (1984). Biological aspects of modeling shoe/foot interaction during running. In E. C. Frederick (Ed.), Sports shoes and playing surfaces (pp. 24-46): Human Kinetics, Champaign.

Frederick, E. C. (1984). Physiological and ergonomics factors in running shoe design. Applied Ergonomics, 15, 281-287.

Garrick, J. G. (1977). The frequency of injury, mechanism of injury, and epidemiology of ankle sprains. The American Journal of Sports Medicine, $\mathbf{5}$, 241-242.

Hamill, J., Freedson, P. S., Boda, W., and Reichsman, F. (1988). Effects of shoe type on cardiorespiratory responses and rearfoot motion during treadmill running. Medicine and Science in Sports and Exercise, 20, 515-521.

Hennig, E., Valiant, G., and Liu, Q. (1996). Biomechanical variables and the 
perception of cushioning for running in various types of footwear. Journal of Applied Biomechanics, 12, 143-150.

Hennig, E. M., and Milani, T. L. (1995). In-shoe pressure distribution for running in various types of footwear. Journal of Applied Biomechanics, 11, 299-310.

Jorgensen, U., and Ekstrand, J. (1988). Significance of heel pad confinement for the shock absorption at heel strike. International Journal of Sports Medicine, 9, 468-473.

Karlsson, J., Peterson, L., Andreasson, G., and Hogfors, C. (1992). The unstable ankle: a combined EMG and biomechanical modeling study. International Journal of Sport Biomechanics, 8, 129-144.

Koepsell, T. D., Wolf, M. E., Buchner, D. M., Kukull, W. A., LaCroix, A. Z., Tencer, A. F., Frankenfeld, C. L., Tautvydas, M., and Larson, E. B. (2004). Footwear style and risk of falls in older adults. Journal of the American Geriatrics Society, 52, 1495-1501.

Konradsen, L., and Ravn, J. B. (1991). Prolonged peroneal reaction time in ankle instability. International Journal of Sports Medicine, 12, 290-292.

Lafortune, M. A., and Lake, M. J. (1995). Human pendulum approach to simulate and quantify locomotor impact loading. Journal of Biomechanics, 28, $1111-1114$

Lake, M. (2000). Determining the protective function of sports footwear. Ergonomics, 43, 1610-1621.

Lake, M. J., and Lafortune, M. A. (1998). Mechanical inputs related to perception of lower extremity impact loading severity. Medicine and Science in Sports and Exercise, 30, 136-143.

Lord, S. R., and Bashford, G. M. (1996). Shoe characteristics and balance in 
older women. Journal of the American Geriatrics Society, 44, 429-433.

Luethi, S. M., Frederick, E. C., Hawes, M. R., and Nigg, B. M. (1986). Influence of shoe construction on lower extremity kinematics and load during lateral movements in tennis. International Journal of Sport Biomechanics, 2, 166-174. Martin, D. R. (1997). How to steer patients toward the right sport shoe. Physician and sportsmedicine (New York), 25, 138-144.

McClay, I. R., Robinson, J. R., Andriacchi, T. P., Frederick, E. C., Gross, T., Martin, P., Valiant, G., Williams, K. R., and Cavanagh, P. R. (1994). A profile of ground reaction forces in professional basketball. Journal of Applied Biomechanics, 10, 222-236.

Milani, T., Hennig, E., and Lafortune, M. (1997). Perceptual and biomechanical variables for running in identical shoe constructions with varying midsole hardness. Clinical Biomechanics, 12, 294-300.

Mundermann, A., Nigg, B. M., Stefanyshyn, D. J., and Humble, R. N. (2002). Development of a reliable method to assess footwear comfort during running. Gait and Posture, 16, 38-45.

Munro, C. F., Miller, D. I., and Fuglevand, A. J. (1987). Ground reaction forces in running: a reexamination. Journal of Biomechanics, 20, 147-155.

Nigg, B. M., and Herzog, W. (1994). Biomechanics of the musculo-skeletal system. New York: John Wiley.

Nigg, B. M., Herzog, W., and Read, L. J. (1988). Effect of viscoelastic shoe insoles on vertical impact forces in heel-toe running. American Journal of Sports Medicine, 16, 70-76.

Simpson, K. J., Shewokis, P. A., Alduwaisan, S., and Reeves, K. T. (1992). Factors influencing rearfoot kinematics during a rapid lateral braking movement. Medicine and Science in Sports and Exercise, 24, 586-594. 
Stacoff, A., Kalin, X., and Stussi, E. (1991). The effects of shoes on the torsion and rearfoot motion in running. Medicine and Science in Sports and Exercise, 23, 482-490.

Stacoff, A., Denoth, J., Kaelin, X., and Stuessi, E. (1988). Running injuries and shoe construction - some possible relationships. International Journal of Sports Biomechanics, 4, 342-357.

Stacoff, A., Steger, J., Stussi, E., and Reinschmidt, C. (1996). Lateral stability in sideward cutting movements. Medicine and Science in Sports and Exercise, $28,350-358$.

Torg, J. S., Quedenfeld, T. C., and Landau, S. (1974). The shoe-surface interface and its relationship to football knee injuries. Journal of Sports Medicine, 2, 261-269.

Voloshin, A., and Wosk, J. (1982). An in vivo study of low back pain and shock absorption in the human locomotor system. Journal of Biomechanics, 15, 21-27.

Weiss, J., De Jong, A., Packer, E., and Bonanni, L. (1981). Purchasing infant shoes: attitudes of parents, pediatricians, and store managers. Pediatrics, 67, 718-720.

Wiseman, L. A. (1990). Protective footwear for leprosy patients with loss of sole sensation: locally made canvas shoes, deepened for a $10-\mathrm{MM}$ rubber insert. Leprosy Review, 61, 291-292. 


\section{Figure caption:}

Figure 1 - The four testing shoes in this study

Figure 2 - Human pendulum used in the cushioning test

Figure 3 - Market set for the motion analysis in the cutting test

Figure 4 - Camera axis and the direction of movement in the cutting test 